\title{
IMPROVING THE FATIGUE STRENGTH OF IMPAIRED WELDS BY OVERLOADING
}

\author{
L'ubomír Gajdoš $^{1}$, Martin Šperl², Andrés Burgos Braga ${ }^{3}$ \\ 1 Institute of Theoretical and Applied Mechanics, Academy of Sciences of the Czech Republic, \\ Prosecká 76, Prague 9, Czech Republic, E-mail: gajdos@itam.cas.cz \\ 2 Institute of Theoretical and Applied Mechanics, Academy of Sciences of the Czech Republic, \\ Prosecká 76, Prague 9, Czech Republic, E-mail: sperl@itam.cas.cz \\ 3 On leave from the Institute of Theoretical and Applied Mechanics, Academy of Sciences of the \\ Czech Republic, Prosecká 76, Prague 9, Czech Republic
}

\section{Introduction}

The defects in the weld can be defined as irregularities in the weld metal produced due to incorrect welding parameters or wrong welding procedures or wrong combination of filler metal and parent metal. Various welding defects can be classified into groups such as cracks, porosity, solid inclusions, lack of fusion and inadequate penetration, imperfect shape and miscellaneous defects. A lack of root fusion (LRF) is one of the weld defects which may develop to a crack and cause failure of the gas pipeline [1]. They also reduce the fatigue limit [2]. In order to investigate the positive effect of overloading of welded joints with LRF on their fatigue properties fatigue tests were carried out on strip-type specimens taken from a helically welded pipe $\varnothing 630 / 7 \mathrm{~mm}$ made from low-C steel ČSN 411373.

\section{Procedure}

The specimens were taken perpendicularly to the weld seam. The weld with LRF was left in the natural state and it was located in the middle of the specimen. The specimens were fatigued in zero-totension loading with the maximum stress in a cycle 132 MPa. Most of the defects of the LRF type were about $0.5 \mathrm{~mm}$ deep; however, by the post-test analysis of the fracture surface there were also some deeper defects found. The results obtained on such specimens were disregarded. The testing program was composed by four groups of specimens, namely groups I to IV - see Tab.1. Group I corresponded to specimens with welds without presence of defects. Group II represented specimens with LRF but without applied overloading. Groups III and IV considered specimens with the existence of LRF and with applied overloading of $0.8 \mathrm{R}_{\mathrm{t} 0.5}$ and $\mathrm{R}_{\mathrm{t} 0.5}$, respectively. In the table, $\mathrm{G}$ stands for group and $\mathrm{O}$ stands for overloading.

\begin{tabular}{|c|c|c|c|c|c|}
\hline \multirow[b]{2}{*}{ G } & \multirow[b]{2}{*}{ No.S } & \multirow[b]{2}{*}{ LRF } & \multirow{2}{*}{$\begin{array}{c}\text { O } \\
{[\mathrm{MPa}]}\end{array}$} & \multicolumn{2}{|c|}{ Stress cycles } \\
\hline & & & & $\begin{array}{l}\sigma_{\min } \\
{[\mathrm{MPa}]}\end{array}$ & $\begin{array}{c}\sigma_{\max } \\
{[\mathrm{MPa}]}\end{array}$ \\
\hline I & $1-5$ & No & --- & 0 & 132 \\
\hline II & $6-10$ & Yes & --- & 0 & 132 \\
\hline III & $11-16$ & Yes & 220 & 0 & 132 \\
\hline IV & $17-22$ & Yes & 276 & 0 & 132 \\
\hline
\end{tabular}

Tab.1. Specimen groups and loading data

After fixing the specimens to the loading machine, they were subjected to their respective overloading and, subsequently, they were excited until the maximum cyclic stress was achieved. A photo of a specimen fixed in the grips of the machine is given on Fig.1.

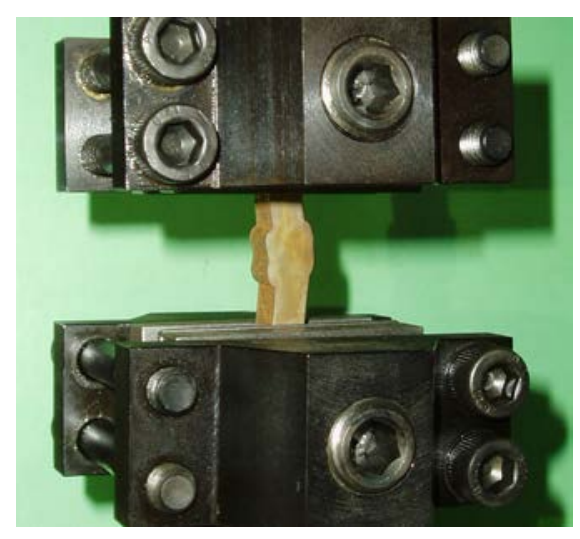

Fig. 1. Specimen fixed in the grips 


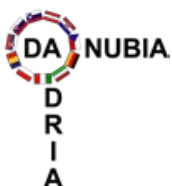

34th Danubia-Adria Symposium on Advances in Experimental Mechanics

University of Trieste, Italy, 2017

\section{Evaluation of the results}

Test results were evaluated assuming the same initial depth of LRF and assuming a Gaussian distributions of logarithms of lives of specimens. A value of life $N_{f}=10^{7}$ was assigned to specimens that did not develop cracking after $10^{7}$ cycles. The outcome of the statistical evaluation is shown in Tab. 2 with the equivalent life at the far-right column. Symbol $\mu$ stands her for the mean and the symbol $s$ stands for the standard deviation of logarithms $N_{f}$. The probability density function of $\log N_{f}$ for all four groups of specimens is presented on Fig. 2.

\begin{tabular}{|c|c|c|c|}
\hline G & $\boldsymbol{\mu}$ & $\boldsymbol{s}$ & $\begin{array}{c}\mathbf{1 0}^{\boldsymbol{\mu}} \\
{[\text { cycles] }}\end{array}$ \\
\hline I & 5.845 & 0.243 & 699,800 \\
\hline II & 5.504 & 0.245 & 319,200 \\
\hline III & 5.843 & 0.104 & 696,600 \\
\hline IV & 6.732 & 0.341 & $5,395,100$ \\
\hline
\end{tabular}

Tab.2. Statistical results. Gaussian distribution of logarithms $N_{f}$

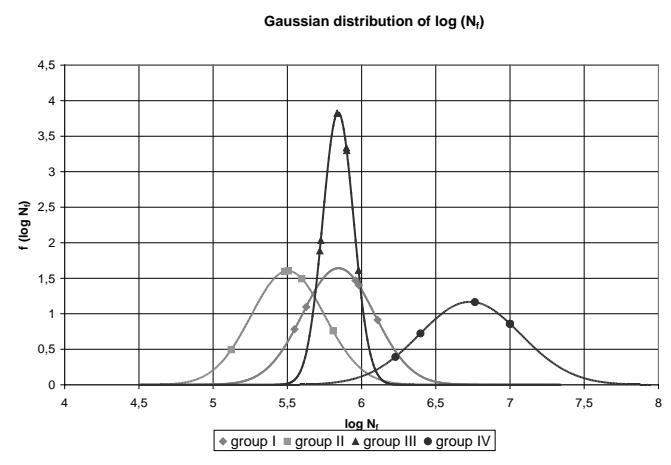

Fig. 2. $f\left(\log N_{f}\right)$ vs. $\log N_{f}$ for tested groups

It is seen from these results that the LRF in welds caused a reduction of the fatigue life by more than a half. The overloading of specimens with LRF to the level of $0.8 \mathrm{R}_{\mathrm{t} 0.5}$ eliminated the influence of the defects, so the achieved fatigue life after tests reached the life expectancy of specimens without LRF. Likewise, the overloading level of $\mathrm{R}_{\mathrm{t} 0.5}$ had an even greater positive impact on the improvement of the fatigue life of the specimens.
Based on a qualitative assessment, the morphological characteristics of the fatigue fracture surfaces of all tested specimens can be considered alike. In areas near the crack initiation site the fracture surface is substantially broken. It consists of a series of micro-facets, separated by micro-steps, without discernible fatigue grooves striations. As the length of a crack increases the fatigue micro-facets widen and fatigue striations start to be discernible (Fig. 3).

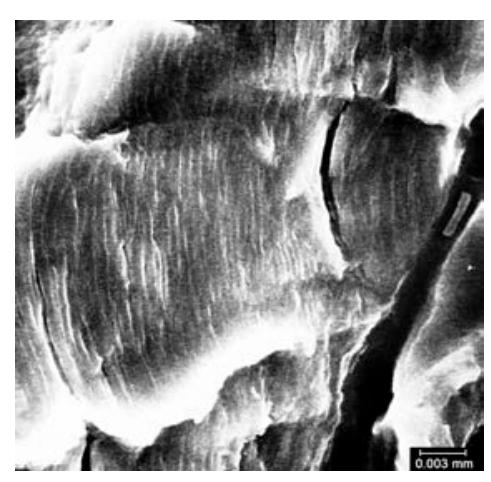

Fig.3. Fatigue microfacets covered by striations

\section{Conclusions}

Because the beneficial effects of overloading as determined in this study can be expected when the level of tensile stress, acting in perpendicular direction to the weld seam, is $(0.8-1.0) \mathrm{R}_{\mathrm{t} 0.5}$, helically welded pipes are disqualified to some extent because even for the hoop stress equal to the yield stress the stress perpendicular to the weld is only a part of the hoop stress. So that full beneficial effects of overloading can be experienced for longitudinally welded pipes only.

\section{Acknowledgements}

This work was supported by the grant project No. TE020000162 of the Technological Grant Agency of the Czech Republic

\section{References}

[1] Gajdoš, L., Šperl, M., Strength of Defective Welds, 18th D-A Symposium, Sept.2001, Steyr, Austria, pp. 79-80

[2] Jaske, C.E., Fatigue Strength Reduction Factors for Welds in Pressure Vessels and Piping. J. Press. Vesel Technol. 122(3), 2000, pp.297-304 